\title{
Diagnosis and management of adult pyogenic osteomyelitis of the cervical spine
}

\author{
Frank L. Acosta Jr., M.D., Cynthia T. Chin, M.D., Alfredo Quiñones-Hinojosa, M.D., \\ Christopher P. Ames, M.D., Philip R. Weinstein, M.D., and Dean Chou, M.D.
}

Departments of Neurological Surgery and Radiology, University of California, San Francisco, California

\begin{abstract}
Establishing the diagnosis of cervical osteomyelitis in a timely fashion is critical to prevent catastrophic neurological injury. In the modern imaging era, magnetic resonance imaging in particular has facilitated the diagnosis of cervical osteomyelitis, even before the onset of neurological signs or symptoms. Nevertheless, despite advancements in diagnosis, disagreement remains regarding appropriate surgical treatment. The role of instrumentation and type of graft material after cervical decompression remain controversial. The authors describe the epidemiological features, pathogenesis, and diagnostic evaluation, and the surgical and nonsurgical interventions that can be used to treat osteomyelitis of the cervical spine. They also review the current debate about the role of instrumentation in preventing spinal deformity after surgical decompression for cervical osteomyelitis. Based on this review, the authors conclude that nonsurgical therapy is appropriate if neurological signs or symptoms, instability, deformity, or spinal cord compression are absent. Surgical decompression, debridement, stabilization, and deformity correction are the goals once the decision to perform surgery has been made. The roles of autogenous graft, instrumentation, and allograft have not been clearly delineated with Class I data, but the authors believe that spinal stability and decompression override creating an environment that can be completely sterilized by antibiotic drugs.
\end{abstract}

\section{KEY WORDS • cervical spine • osteomyelitis • instability • fixation}

According to Dimar, et al., ${ }^{15}$ Hippocrates was the first to describe osteomyelitis of the spine in 400 BCE. In 1864, as discussed in Wiltse ${ }^{67}$ Boudof described draining an abscess of the cervical spine via an anterior approach. In the same historical review, Wiltse reported Wright's account of draining a tuberculous abscess through the pharynx in 1930. Although the advent of antibiotic therapy enabled early stages of vertebral osteomyelitis to be managed without surgery, more advanced disease with spinal instability, cord compression, and neurological deficits required surgical decompression and stabilization. ${ }^{7,54}$ Nonetheless, anterior approaches to the cervical spine were seldom used until Robinson and Smith ${ }^{50}$ described a technique for anterior cervical disc removal and fusion in 1955. Current surgical treatment options include anterior or posterior decompression with or without fusion, and with or without instrumentation. ${ }^{16,24,35,36,39,40}$ The fact that there exist several alternative surgical approaches highlights the lack of a consensus on the optimal operative treatment for cervical vertebral osteomyelitis.

The large diameter of the cervical spinal cord relative to the spinal canal and the significant range of motion of the

Abbreviations used in this paper: CRP = C-reactive protein; $\mathrm{CT}=$ computerized tomography $; \mathrm{ESR}=$ erythrocyte sedimentation rate; $\mathrm{MR}=$ magnetic resonance; $\mathrm{VB}=$ vertebral body; $\mathrm{WBC}=$ white blood cell. cervical spine make cervical osteomyelitis a unique entity. A small epidural infection can cause a neurological deficit. Bone destruction and ligamentous laxity can manifest as severe instability, deformity, or a neurological deficit. ${ }^{13}$ Establishing the diagnosis of cervical osteomyelitis in a timely fashion is critical to prevent catastrophic neurological injury. ${ }^{15,41}$ In the modern imaging era, MR imaging in particular has facilitated the diagnosis of cervical osteomyelitis even before the onset of neurological signs or symptoms. Nevertheless, despite advancements in diagnosis, there remains disagreement regarding appropriate surgical treatment. The role of instrumentation and type of graft material after cervical decompression remain controversial. We describe the epidemiological features, pathogenesis, diagnostic evaluation, and surgical and nonsurgical interventions that can be used to treat osteomyelitis of the cervical spine. We also review the current debate about the role of instrumentation in preventing spinal deformity after surgical decompression for cervical osteomyelitis.

\section{EPIDEMIOLOGY AND ETIOLOGY}

Vertebral osteomyelitis accounts for approximately 1 to $7 \%$ of all bone infections. ${ }^{13,57}$ Whereas the thoracic and lumbar spine are affected in 35 and $50 \%$ of cases, respectively, the cervical region is affected in 3 to $10 \%$ of cases. ${ }^{25,38,57,60}$ Although relatively rare, cervical osteomye- 
F. L. Acosta, et al.

litis nonetheless poses management challenges to the spine surgeon, given the location of the disease process.

Pyogenic vertebral osteomyelitis refers to bacterial infections of the spine that cause purulence and a predominantly neutrophilic response. ${ }^{64}$ It encompasses a spectrum of pathological conditions, including discitis, spondylitis, and spondylodiscitis. ${ }^{25}$ Epidural abscess often complicates these disease processes. ${ }^{25}$ There appears to be an increasing incidence of spinal infections in recent years; this disease is now estimated to occur in approximately 1 per 100,000 persons annually. ${ }^{10,29}$ This rise can be attributed to the increasing prevalence of elderly and immunocompromised individuals in the population. ${ }^{13}$ Cervical osteomyelitis most often affects patients in the fifth through seventh decades of life. ${ }^{38,57}$ Patients with diabetes, a history of intravenous drug abuse, chronic immunosuppression, or human immunodeficiency virus are particularly susceptible to vertebral osteomyelitis. ${ }^{5,13,23,26,44,54}$ Cervical osteomyelitis has been reported to occur in up to $27 \%$ of intravenous drug abusers..$^{56,60}$

The most common mechanism for spread to the cervical spine is through a hematogenous route. Remote infections anywhere in the body can seed the spine. Patients with primary pulmonary tuberculosis can present with tuberculous osteomyelitis of the spine. ${ }^{11,69}$ Urinary tract infections, respiratory tract infections, and intravenous drug abuse are very common sources of spinal osteomyelitis. ${ }^{54,55}$ Moreover, the cervical spine is particularly susceptible to infection that spreads from adjacent tissues, or that occurs from contamination after invasive diagnostic or therapeutic procedures. For example, osteomyelitis of the cervical spine has been reported to occur after tracheotomy, ${ }^{45}$ pharyngeal surgery, ${ }^{17}$ tonsillectomy, ${ }^{14}$ cervical discography, ${ }^{73}$ and in association with Zenker diverticulum. ${ }^{22}$ Cervical spinal infection has also been reported to occur after cervical spine trauma. ${ }^{32,37}$ Hematogenous seeding, though, remains the most common route for spread of infection to the cervical spine..$^{13,57,71}$

\section{MICROBIOLOGY}

The predominant organism in almost all studies is Staphylococcus aureus, accounting for approximately 40 to $80 \%$ of all spinal infections..$^{25,29}$ Other Gram-positive organisms such as S. epidermidis and Streptococcus species are the second most common ones. ${ }^{18,25}$ Since the introduction of antibiotics, though, there has been a relative increase in infections caused by Gram-negative bacteria such as Escherichia coli and diphtheroids. ${ }^{13,25}$ Pseudomonas is frequently identified in intravenous drug abusers. ${ }^{54,55,66,70}$ Gram-negative rods such as Salmonella and Proteus species are less common and are generally associated with gastrointestinal or genitourinary sources of infection. ${ }^{13,54,55}$ Anaerobic bacteria such as Peptostreptococcus and Bacteroides are infrequent causes of spinal infection. ${ }^{64}$ Polymicrobial infections and negative cultures are found in approximately $20 \%$ of patients (Table 1)..$^{25,54,55}$ Concurrent administration of antibiotic medications before biopsy sampling, an inadequate tissue sample, and the normal healing process of the intervertebral disc space have all been proposed as explanations for the inability to isolate an organism from infected tissue. ${ }^{20,25,61}$
TABLE 1

Literature review of the microorganisms identified in cultures obtained in patients with cervical osteomyelitis

\begin{tabular}{lllll}
\hline \hline & \multicolumn{4}{c}{ Study, No. of Patients (\%) } \\
\cline { 2 - 5 } \multicolumn{1}{c}{ Microorganism } & $\begin{array}{c}\text { Schimmer, } \\
\text { et al. }\end{array}$ & $\begin{array}{l}\text { Shad, } \\
\text { et al. }\end{array}$ & $\begin{array}{c}\text { Spies, } \\
\text { et al.* }\end{array}$ & $\begin{array}{c}\text { Dimar, } \\
\text { et al. }\end{array}$ \\
\hline $\begin{array}{l}\text { S. aureus } \\
\text { coagulase-negative }\end{array}$ & $8(53)$ & $4(80)$ & $1(33)$ & $3(60)$ \\
$\quad 0$ & $1(20)$ & 0 & 0 \\
$\begin{array}{l}\text { Staphylococci } \\
\text { Klebsiella pneumoniae }\end{array}$ & $1(7)$ & 0 & 0 & 0 \\
$\begin{array}{l}\text { Mycobacterium } \\
\text { tuberculosis }\end{array}$ & $1(7)$ & 0 & 0 & 0 \\
$\begin{array}{l}\text { Streptococcus } \text { sp. } \\
\text { none isolated }\end{array}$ & $1(7)$ & 0 & 0 & 0 \\
polymicrobial & $2(13)$ & 0 & $1(33)$ & $2(40)$ \\
total no. of patients & 0 & 0 & $1(33)$ & 0 \\
\end{tabular}

* All affected patients in this study had osteomyelitis of the C1-2 complex.

\section{PATHOGENESIS}

The unique vascular supply to the intervertebral disc space in general, and to the cervical spine in particular, can be used to explain the pathogenesis of cervical osteomyelitis. The spine is inoculated with infectious organisms through the arterial blood supply, direct inoculation during an invasive procedure, direct extension from an adjacent nidus of infection, or retrogradely through the vertebral venous plexus. ${ }^{64}$ Infection through the arterial blood supply likely accounts for most cases; periosteal arteries can carry bacteria into the small metaphysial nutrient arteries to which they give rise, setting up a nidus of infection and causing avascular necrosis of the metaphysis. The intervertebral disc, supplied by these same vessels, also becomes infected and necrotic. Inoculation of a metaphysial artery can therefore lead to infection of both the disc space and adjacent vertebrae. ${ }^{14,32,73}$ Accordingly, it is believed that discitis and vertebral osteomyelitis are different stages of the same disease process. ${ }^{25}$ Spontaneous infection of the disc space rarely occurs. ${ }^{13}$

Infectious organisms within the genitourinary or gastrointestinal systems can spread to the spine through epidural veins. ${ }^{59}$ This type of transvenous inoculation is believed to be the major mechanism in the development of rare infections involving the posterior elements of the spine. ${ }^{2,64}$ Moreover, infection within the disc space or adjacent VBs can be transmitted to the epidural space through the epidural venous plexus to form an epidural abscess. ${ }^{64}$ In the upper cervical spine, the odontoid process is surrounded by a large venous plexus that has anastomoses with the venous drainage of the posterior superior nasopharynx. This communication is believed to be responsible for infections of the upper cervical spine and odontoid process, particularly after invasive procedures of the pharyngeal region. ${ }^{33,34,48,60,62,65,72}$

\section{CLINICAL PRESENTATION}

A high index of suspicion is central to the diagnosis of cervical osteomyelitis. This is particularly true for patients 


\section{Diagnosis and management of adult pyogenic spinal osteomyelitis}

with a history of intravenous drug abuse, immunocompromise, and those with chronic renal failure. Before the onset of neurological deficits, the clinical presentation of cervical osteomyelitis is generally vague and nonspecific (Table 2), and because of this, there is often a delay between the onset of symptoms and the diagnosis. ${ }^{15}$ Pain is almost always present, and in some cases can lead to severe spasm, causing torticollis. ${ }^{13,57} \mathrm{Up}$ to $50 \%$ of patients have fever, although this symptom may be absent early in the course of the illness. ${ }^{55,57}$ Patients with severe infection and immunocompromised individuals can present in florid sepsis. ${ }^{13,64}$ When the occipitocervical junction is involved, occipital headache and constitutional symptoms such as weight loss may be present initially ${ }^{57}$ Neurological symptoms have been found to occur in as many as $60 \%$ of patients with cervical osteomyelitis, compared with 5 to $20 \%$ of all patients with infection of the thoracic or lumbar spine..$^{57,64}$ The fact that neurological deficits are so common in the cervical region can be explained by the relatively small cross-sectional diameter of the bone of the spinal canal relative to the diameter of the cervical spinal cord. Thus, neurological deficits can occur as a result of direct spinal cord compression by epidural abscess, segmental deformity, instability, and as a result of disc disruption from discitis..$^{58}$ In contrast, the lumbar spinal canal is relatively wide compared with the conus medullaris and the cauda equina, and serious neurological deficits from infections of the lumbar spine occur in only approximately $5 \%$ of cases. ${ }^{15}$ Neurological deficits in cervical osteomyelitis can range from cervical radiculopathy to complete quadriplegia. ${ }^{57}$ Immunocompromised patients often have a more acute presentation than others and are therefore most likely to experience neurological deficits from spinal infection. ${ }^{7,16,64}$

Physical examination may reveal tenderness over the affected segment, pain with passive neck movement, or a gibbous deformity. ${ }^{64} \mathrm{~A}$ dermatomal level of sensory and/

TABLE 2

Literature review of clinical features in patients with cervical osteomyelitis*

\begin{tabular}{|c|c|c|c|c|c|}
\hline \multirow[b]{2}{*}{ Authors \& Year } & \multirow[b]{2}{*}{$\begin{array}{c}\text { No. } \\
\text { of } \\
\text { Patients }\end{array}$} & \multirow[b]{2}{*}{$\begin{array}{l}\text { Location } \\
\text { of } \\
\text { Infection }\end{array}$} & \multicolumn{3}{|c|}{ Presenting Sx/Signs } \\
\hline & & & $\begin{array}{l}\text { Neuro } \\
\text { Deficit } \\
(\%)\end{array}$ & $\begin{array}{l}\text { Neck } \\
\text { Pain } \\
(\%)\end{array}$ & $\begin{array}{l}\text { Const } \\
\text { Sx } \\
(\%)\end{array}$ \\
\hline $\begin{array}{l}\text { Spies, et al., } \\
1999\end{array}$ & 3 & $\begin{array}{l}\text { occipitocervical } \\
\text { junction }\end{array}$ & $0(0)$ & $3(100)$ & $3(100)$ \\
\hline $\begin{array}{l}\text { Schimmer, } \\
\text { et al., } 2002\end{array}$ & 15 & $\begin{array}{l}\text { C1-2 in } 2 ; \\
\text { C3-5 \& } \\
\text { C4-5 in } 1 \text { each; } \\
\text { C5-6 in 6; } \\
\text { C6-7 in 3; } \\
\text { C7-T1 in } 2\end{array}$ & $9(60)$ & $15(100)$ & $7(47)$ \\
\hline $\begin{array}{l}\text { Shad, et al., } \\
2003\end{array}$ & 5 & $\begin{array}{l}\text { C4-5 in } 2 \text {; } \\
\text { C-2, C3-4, } \\
\& \text { C } 5-6 \text { in } \\
1 \text { each }\end{array}$ & $5(100)$ & $5(100)$ & NR \\
\hline $\begin{array}{l}\text { Suchomel, } \\
\text { et al., } 2003\end{array}$ & 3 & $\begin{array}{l}\text { odontoid } \\
\text { process }\end{array}$ & $0(0)$ & $3(100)$ & $3(100)$ \\
\hline
\end{tabular}

$*$ Const $=$ constitutional neuro $=$ neurological $; \mathrm{NR}=$ not reported $; \mathrm{Sx}=$ symptoms. or motor deficit is common. Acute osteomyelitis with epidural abscess formation can cause spinal cord injury with bladder and bowel involvement. It is thus useful to measure the postvoid residual volume in all patients suspected of having cervical osteomyelitis. The development of neurological deficits can correlate with the rate of progression of infection; chronic, indolent infections rarely present with acute neurological decline, whereas a rapidly progressing infection can result in acute neurological deficits.

\section{Laboratory Evaluation}

Laboratory markers of systemic infection, including WBC count, ESR, and CRP level are useful in the initial screening of patients suspected of having a spinal infection, especially when initial neuroimaging studies are nondiagnostic. ${ }^{64}$ The ESR has been found to be a more sensitive test of spinal infection, because it is elevated in 70 to $100 \%$ of cases, compared with only 13 to $60 \%$ of cases in which an elevated leukocyte count is identified. ${ }^{18,25,49}$ In the presence of an epidural abscess, however, the leukocyte count has a sensitivity of $90 \%$, and the ESR has a sensitivity of $100 \% .{ }^{25}$ Neither of these tests are specific for spinal infection. Like the ESR, the CRP level is a more sensitive indicator of spinal infection than the leukocyte count. ${ }^{15}$ Both the ESR and CRP level may be useful in evaluating response to treatment. ${ }^{13}$

\section{Diagnostic Neuroimaging}

The diagnosis of cervical osteomyelitis is first established on neuroimages and later confirmed with tissue samples to determine the causative organism. ${ }^{57}$ Plain $\mathrm{x}$-ray films can demonstrate end plate erosion, although they often depict normal anatomy until 2 to 4 weeks after the onset of infection. ${ }^{13,15,64}$ Plain x-ray films can also show other changes that occur weeks after the onset of infection, such as paravertebral soft-tissue edema, disk height loss, and eventually vertebral collapse and kyphotic deformity (Fig. 1A). ${ }^{13}$

Use of CT scans with sagittal and axial three-dimensional reconstructions can further delineate bone destruction (Fig. 1B). Contrast-enhanced CT scans can reveal paravertebral soft-tissue inflammation, enhancing epidural collections, and intradiscal and intravertebral abscesses. ${ }^{15,64}$ The CT-guided percutaneous aspiration of an infected spinal segment or fluid collection provides tissue for identification of a causative organism (Fig. 2). Finally, CT myelography is useful in demonstrating spinal cord compression from an epidural abscess when MR imaging cannot be performed. ${ }^{57}$

Magnetic resonance imaging with and without Gd contrast is the gold standard in the diagnosis of cervical osteomyelitis. ${ }^{30}$ This modality has a 96\% sensitivity, 93\% specificity, and $94 \%$ accuracy in detecting vertebral osteomyelitis. ${ }^{15,43}$ The $\mathrm{T}_{1}$-weighted precontrast MR images can reveal a loss of disc height, hypointensity of the vertebral end plates, and a loss of the normally hyperintense marrow signal within the VB (Fig. 3B). ${ }^{19,23,30,42,64}$ Prevertebral and retropharyngeal abscesses may be the only findings on MR imaging in some cases of cervical osteomyelitis., ${ }^{3,1952}$ Disc space edema and edema within the VB appear as hyperintense signals on $\mathrm{T}_{2}$-weighted MR images. Paravertebral edema is also hyperintense on $\mathrm{T}_{2}$-weighted 


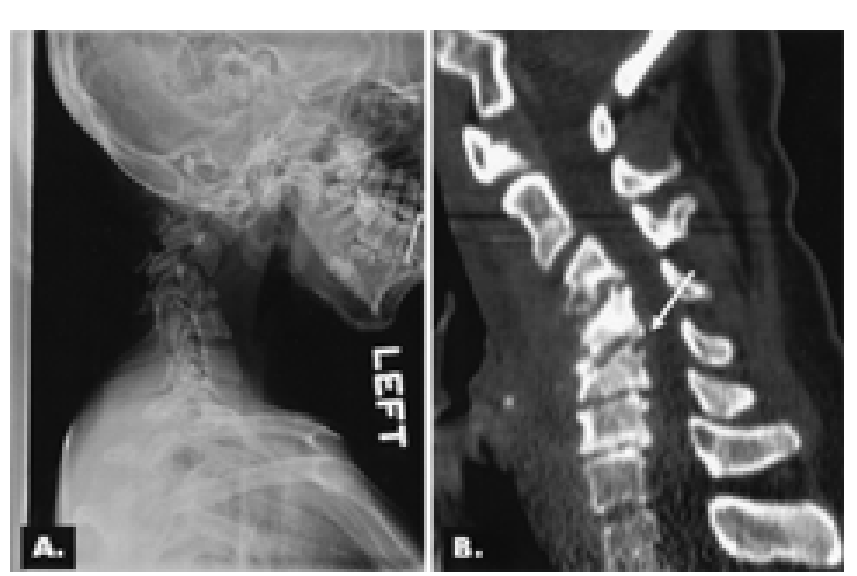

Fig. 1. A: Lateral cervical plain X-ray film showing collapse of the C-4 VB and a marked kyphotic deformity in a patient with cervical osteomyelitis caused by methicillin-resistant $S$. aureus. B: Sagittal CT reconstruction obtained in the same patient, demonstrating significant prevertebral soft-tissue swelling extending from C2-6. The end plates of C-3, C-4, C-5, and C-6 are irregular and sclerotic, and collapse of the VBs compatible with osteomyelitis resulting in kyphosis is observed. Posterior to the VBs in the epidural space, soft tissue is seen from $\mathrm{C} 3-6$, which may represent phlegmon and/or abscess (arrow). In combination with the kyphosis, this results in spinal cord compression.

images (Fig. 3A).,30,42 Post-contrast $\mathrm{T}_{1}$-weighted images are the most sensitive diagnostic images of the MR modality. Enhancement of the vertebral end plate, VB, paravertebral soft tissues, and epidural space can be seen (Fig. 3C). . $^{30,42}$

Radionuclide bone scans such as ${ }^{67} \mathrm{Ga}$ and ${ }^{99} \mathrm{Tc}$ scans are

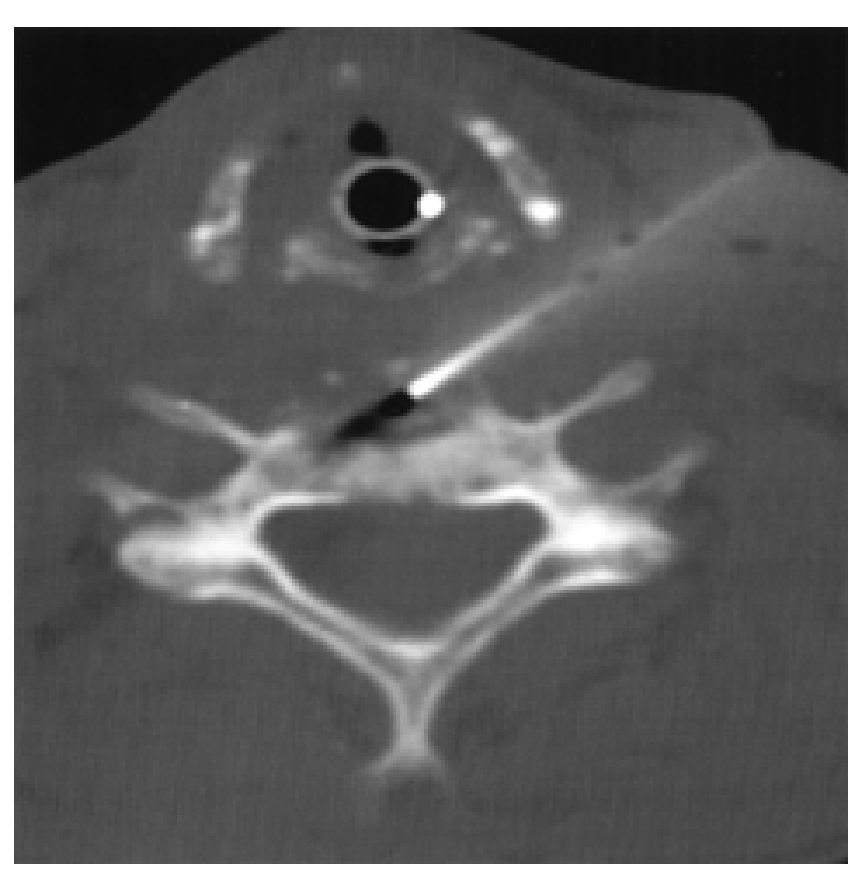

Fig. 2. Axial CT scan obtained through C5-6 during CT-guided biopsy sampling; a 20-gauge Chiba needle was used. Bloody fluid was aspirated that was positive in culture for Candida. both reasonably sensitive and specific for the detection of pyogenic vertebral osteomyelitis. The ${ }^{67} \mathrm{Ga}$ scans are more specific because Ga binds to iron-binding proteins at the site of inflammation. ${ }^{46}$ The ${ }^{111}$ In-tagged WBC scans are more specific for infection than either Ga or Tc scans, although they can lead to false-negative results in cases of chronic inflammation. ${ }^{64}$ Although these radioisotope scans, particularly tagged WBC scans, can be useful in the diagnosis of spinal infection in cases in which MR images are equivocal, false-positive results can be seen in the case of spinal tumors and after trauma. ${ }^{64}$

\section{Bacteriological Diagnosis}

The differential diagnosis of pyogenic cervical osteomyelitis includes nonpyogenic (tubercular or fungal) osteomyelitis, lymphoma, rheumatoid arthritis, metastatic tumor, trauma, granulomatous infection, degenerative spondylosis, and avascular necrosis of the VB (Table 3). ${ }^{13,60}$ The final diagnosis of cervical osteomyelitis hinges on isolating a definitive organism in culture. Blood cultures are positive in only approximately 20 to $60 \%$ of patients with spinal infection, and urine cultures are not reliable indicators of spinal infection. ${ }^{13,55}$ Needle biopsy sampling of the cervical spine under fluoroscopic or CT guidance has been performed safely with large-bore needles; ${ }^{12,47,63}$ however, this examination may yield false-negative results, especially if the patient has been treated with antibiotic drugs or if a small-bore needle is used..$^{53,61,64} \mathrm{It}$ is important to withhold all antibiotic medications until a definitive organism is isolated, unless the patient is septic or hemodynamically unstable..$^{21,54,55}$

Mycobacterial or fungal infections should be considered in patients in whom results of cultures are persistently negative despite repeated tissue samples. ${ }^{64}$ In the presence of an epidural abscess with or without neurological deficit, or if an organism cannot be isolated on repeated closed biopsy procedures, an open biopsy with surgical debridement is required. ${ }^{57}$ Open biopsy procedures have a lower false-negative rate than the percutaneous-needle method and allow for grossly abnormal tissue to be submitted to the pathologist. ${ }^{13,55}$ It is important to obtain a full assessment of a patient with a pyogenic spinal infection. This includes examination and diagnostic evaluation for extraspinal sequelae of infection, including endocarditis, longus colli muscle abscess, meningitis, and retropharyngeal abscesses. ${ }^{52,57,64}$

\section{MANAGEMENT PROTOCOLS}

Although cervical osteomyelitis may be managed with antibiotic medications alone without surgery, any surgically based therapy requires concomitant and prolonged treatment with antibiotic drugs. Before the advent of antibiotics, 40 to $70 \%$ of patients with spinal infections died. ${ }^{68}$

\section{Nonsurgical Management}

Nonsurgical management consisting of antibiotic therapy and external immobilization is feasible in the absence of a large epidural abscess, significant neurological deficit, or bone destruction. ${ }^{25,57}$ Patients with overt signs of sepsis should be treated with intravenous broad-spectrum antibiotic drugs as soon as tissue is obtained for culture. ${ }^{13}$ 

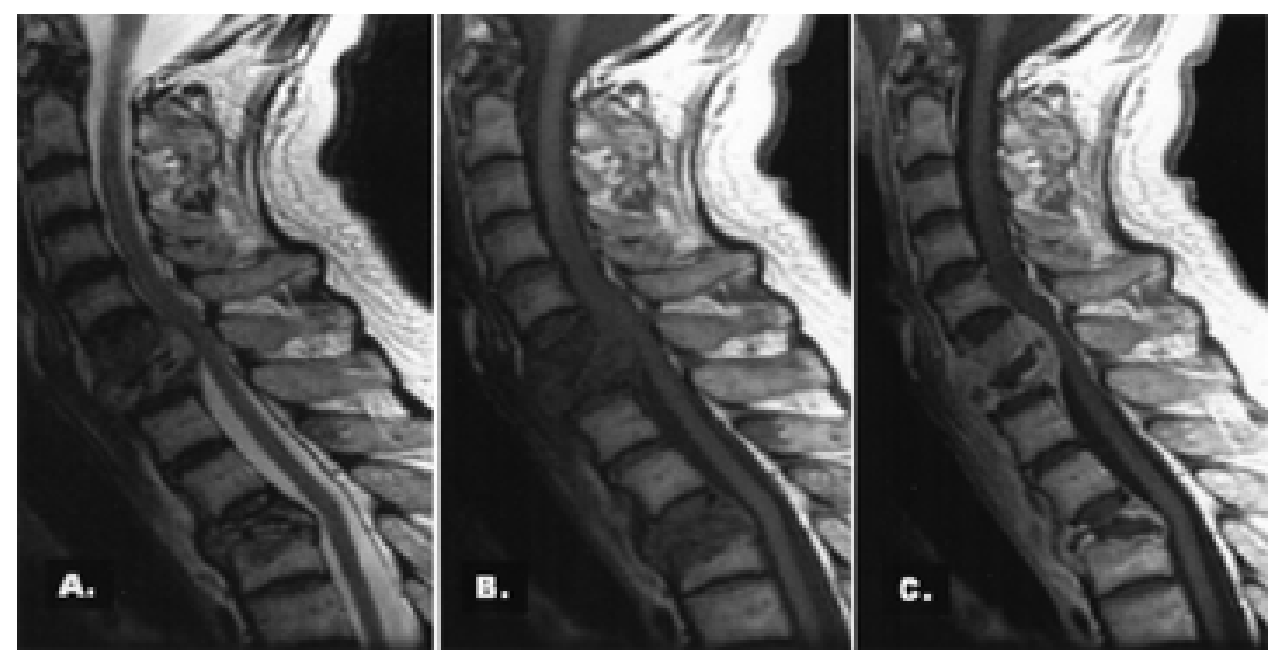

Fig. 3. A: Preoperative sagittal $\mathrm{T}_{2}$-weighted $\mathrm{MR}$ image demonstrating erosion and loss of height of the C-6, C-7, and T-3 VBs. There is an abnormally high-intensity $\mathrm{T}_{2}$ signal, and spinal cord compression at C6-7 and associated kyphosis at T-3 are also evident. $\quad B$ and $C$ : Sagittal $T_{1}$-weighted precontrast MR image (B) revealing low-intensity $T_{1}$ signal in the involved vertebrae, which enhances in the postcontrast MR image (C). This patient had osteomyelitis due to Corynebacterium.

Antibiotic therapy can then be tailored according to the culture and sensitivity results. Intravenous antibiotic drugs should be administered for 6 to 8 weeks, followed by a 6-week course of oral antibiotics until the infection is cured. $^{25}$ Treatment with less than 4 weeks of antibiotic therapy is associated with a $25 \%$ relapse rate. ${ }^{13,16,54,55}$ The ESR can be expected to decrease to one half to two thirds of pretreatment levels on successful treatment. ${ }^{51,54,55,64}$

Cervical immobilization should be used to control pain and to prevent deformity and neurological deterioration. ${ }^{25}$ Immobilization should be achieved with a halo device because deformity from cervical osteomyelitis progresses rapidly, eventually causing instability. ${ }^{13}$ Immobilization should be used for at least 3 to 4 months; however, bone ankylosis typically requires 6 to 24 months, ${ }^{25}$ and spontaneous fusion occurs in only $35 \%$ of cases (Fig. 4). ${ }^{21} \mathrm{Al}$ though neurological deficits have been shown to resolve with medical treatment, mechanical neck pain often persists and some patients may continue to deteriorate despite

TABLE 3

Differential diagnosis of cervical osteomyelitis*

\begin{tabular}{cc}
\hline \hline Differential Diagnosis & Distinguishing Neuroimaging Features \\
\hline $\begin{array}{c}\text { nonpyogenic (tubercular or } \\
\text { fungal) osteomyelitis }\end{array}$ & $\mathrm{VB}>$ disc space affected; early \\
paravertebral abscess formation
\end{tabular}

fungal) osteomyelitis

metastatic tumor

lymphoma $\dagger$

degenerative spondylosis

vertebral avascular necrosis

dehydrated disc hypointense on $\mathrm{T}_{2^{-}}$ weighted images

significant VB collapse; intravertebral vacuum clefts

rheumatoid arthritis

* Differential diagnosis for patients suspected of having osteomyelitis of the cervical spine based on clinical and neuroimaging findings. Criteria were outlined in studies by Tandon and Vollmer and by Wood.

$\dagger$ Especially in immunosuppressed patients. weeks of antibiotic treatment and cervical immobilization..$^{25,27,47}$ Progressive deformity and pseudarthrosis instability are the most common causes of these problems with nonsurgical treatment. ${ }^{25}$

\section{Surgical Management}

Surgical treatment of cervical osteomyelitis is indicated in cases of significant neurological deficit, spinal deformity, or instability. Persistent pain, septicemia despite antibiotic treatment, or attempts to establish a diagnosis are also indications for surgery (Table 4) ${ }^{16,18,28}$ Patients with disabling neck pain have a better clinical outcome when treated surgically. ${ }^{25}$ The principles of surgical treatment in spinal osteomyelitis include removal of infected tissue, restoration of neurological function, restoration of sagittal and coronal plane alignment, and spinal stabilization to prevent further deformity, pain, or neurological deficit. ${ }^{57}$

As a general rule, an anterior approach is used for lesions causing ventral compression, and a posterior approach is used for lesions causing dorsal compression of the spinal cord. ${ }^{64}$ Because most infections and deformities of the cervical spine are situated anterior to the cord, surgical debridement with or without internal fixation is usually first performed via this approach (Fig. 5).$^{15,18,58}$ In the absence of gross purulence, a one-step anterior debridement and fusion with bone graft is performed. ${ }^{57}$ Although some authors have reported successful treatment of cervical osteomyelitis with single-stage anterior debridement and fusion, even in the presence of purulence, ${ }^{18}$ most recommend anterior debridement alone with application of a halo device postoperatively, ${ }^{18,58}$ followed by delayed secondary debridement and anterior fusion after a period of 7 to 14 days of intravenous antibiotic treatment. ${ }^{15,57}$ If there is a significant amount of bone destruction causing instability or deformity, combined anterior and posterior fusion and internal fixation with a lateral mass screw/rod construct provides better stabilization (Fig. 6).$^{58}$ At our in- 


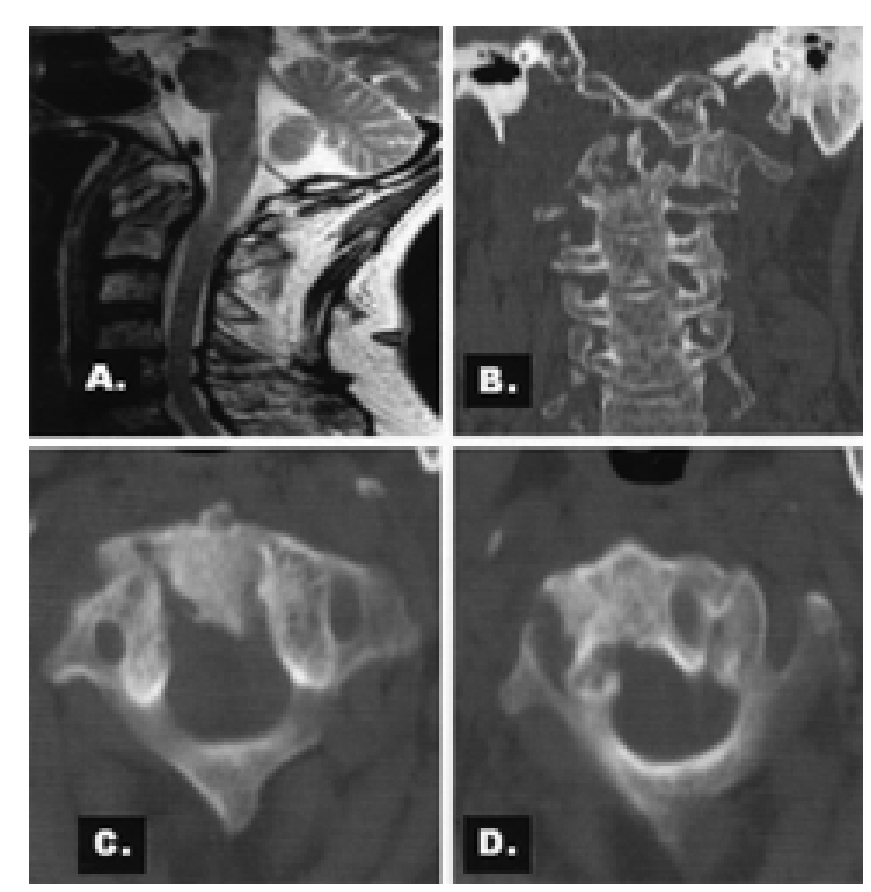

Fig. 4. Neuroimages obtained in a 79-year-old man with osteomyelitis due to methicillin-resistant $S$. aureus. A: Sagittal $\mathrm{T}_{2}$-weighted $\mathrm{MR}$ sequence demonstrating $\mathrm{C} 1-2$ prevertebral and epidural tissue with a high-intensity $\mathrm{T}_{2}$ signal compatible with abscess. B: Coronal reformatted $\mathrm{CT}$ scan demonstrating erosion of the C-1 anterior arch and right lateral mass and odontoid process. $\mathrm{C}$ and D: Axial CT scans obtained through C1-2 after intravenous antibiotic treatment, demonstrating interval autofusion of the odontoid to the anterior $\mathrm{C}-1$ arch and $\mathrm{C}-2$ body to $\mathrm{C}-1$ lateral mass.

stitution, we prefer to perform a $360^{\circ}$ operation if the bone destruction is severe, the surgical defect results in an incredibly destabilized spine, if bone quality is extremely poor, or if compliance with external orthosis will not be high.

A posterior laminectomy alone is indicated only for decompression in cases of primary epidural abscess, and should be followed by posterior stabilization. ${ }^{1,25}$ If there is significant kyphosis, an anterior procedure to correct the deformity would be indicated in addition to the posterior

TABLE 4

Clinical and neuroimaging indications for surgical treatment of cervical osteomyelitis*

\begin{tabular}{ll}
\hline \hline \multicolumn{1}{c}{ Clinical Signs } & \multicolumn{1}{c}{ Imaging Features } \\
\hline $\begin{array}{l}\text { severe neurological deficit† } \\
\text { persistent septicemia despite } \\
\text { antibiotic therapy }\end{array}$ & $\begin{array}{l}\text { pathological fracture } \\
\text { paravertebral or epidural abscess } \\
\text { intractable pain }\end{array}$ \\
& $\begin{array}{c}\text { significant sagittal or coronal plane } \\
\text { deformity } \\
\end{array}$ \\
& spinal instability \\
\hline
\end{tabular}

* According to criteria outlined by Currier and by Schimmer, et al. Surgical treatment is also indicated in cases in which the bacteriological diagnosis cannot be established by cultures of biopsy samples.

$\uparrow$ Does not include minimal deficits such as radiculopathy.

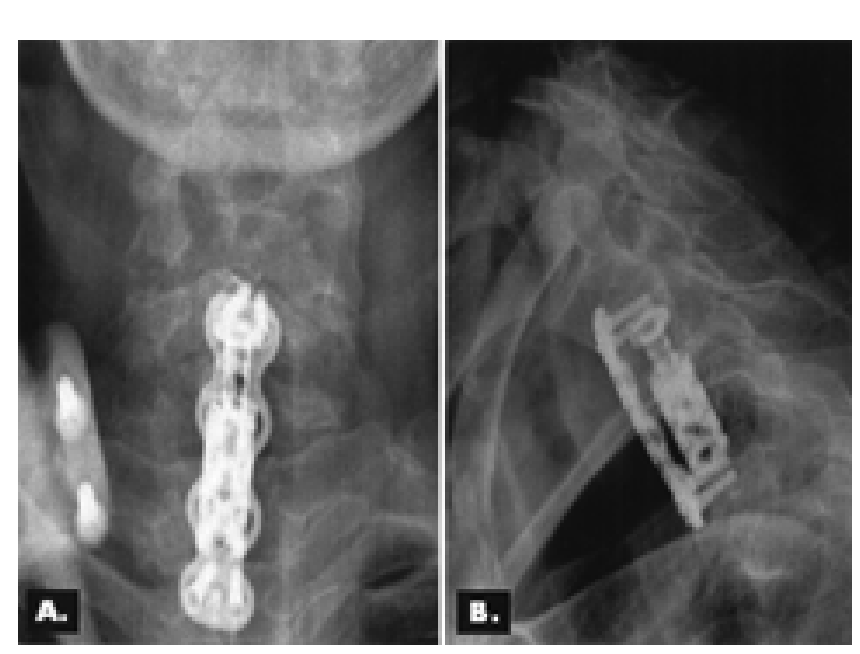

Fig. 5. Anteroposterior (A) and lateral (B) plain X-ray films demonstrating anterior interbody fusion from C6-T1. Preoperative images of this patient are shown in Fig. 3 .

procedure. If the loss of lordosis is minimal, or the patient is young, posterior instrumentation should be considered to prevent postlaminectomy kyphosis. ${ }^{1}$

\section{Fusion and Internal Fixation of the Infected Cervical Spine}

The use of bone graft and instrumentation for internal fixation, particularly in the setting of an already infected spine, raises the concern of secondary infection from these devices. Indeed, delayed secondary infection after surgical debridement and internal fixation has been reported more than 1 year postsurgery and may actually represent an incompletely treated primary infection. ${ }^{18,58}$ Shad, et al., ${ }^{58}$ found that four of five patients with cervical osteomyelitis had bacterial colonization of implanted fixation devices after surgical decompression and primary internal fixation followed by 3 months of intravenous antibiotics. These authors recommend long-term oral antibiotic therapy after insertion of metallic instrumentation for cervical osteomyelitis, followed by removal of all implants and repeated culturing. ${ }^{58}$ Nevertheless, the advantages of singlestage decompression and fixation, including shortened hospital stay, avoiding a second procedure under anesthesia, and obviating the need for external fixation, are significant and this procedure continues to be used successfully. ${ }^{57,62}$ At our institution, we believe that autograft is ideal in light of an infection. Nevertheless, we recognize that there are times when autograft is simply not practical. Very long constructs after multilevel corpectomies requiring a large straight graft, a patient's desires to avoid iliac crest harvesting, previous harvesting of iliac crest, and the avoidance of another incision are some reasons to use allograft.

\section{PROGNOSIS}

Patients with cervical osteomyelitis with incomplete neurological deficits often recover normal function after prompt surgical decompression. ${ }^{38,51,56,57}$ The prognosis is more guarded in patients presenting with complete neu- 


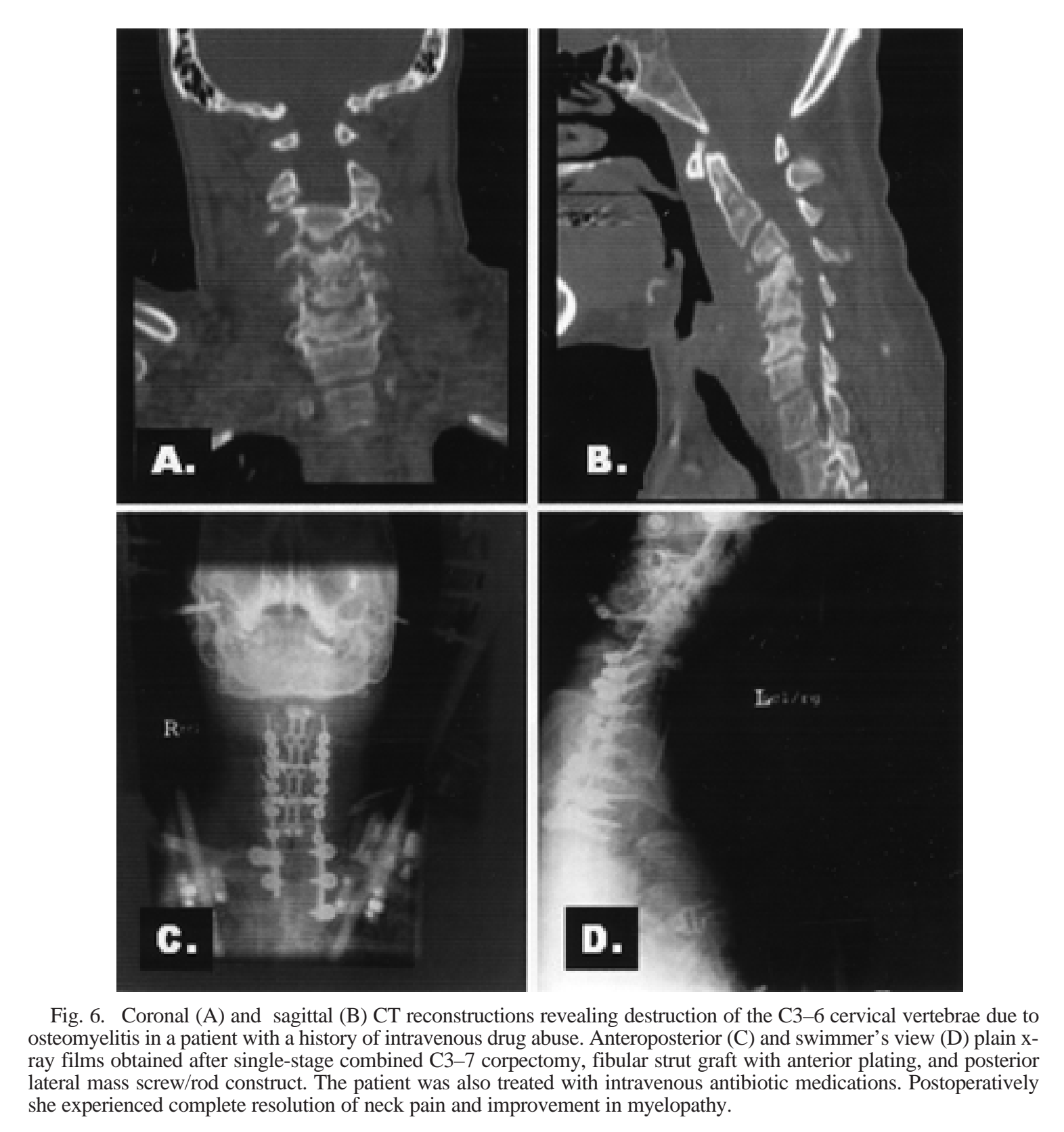

rological deficits, or in whom diagnosis and treatment are delayed. Khanna, et al., ${ }^{31}$ found that for patients with epidural abscesses, outcome was worse in older patients, and in those presenting with sepsis, with more than 72 hours of neurological deficit, or with significant spinal cord compression. For patients treated nonsurgically, outcome depends on age, rate of decrease in ESR, immune state, and virulence of the infecting organism ( $S$. aureus being particularly virulent) ${ }^{8,64}$ Neuroimaging evidence of successful treatment lags significantly behind clinical response and is not useful in determining response to treatment. ${ }^{6,9}$

\section{CONCLUSIONS}

Cervical osteomyelitis is a diagnosis that should be recognized if patients have the appropriate risk factors, signs, and symptoms. Definitive diagnosis in the modern neuroimaging era is usually made with MR imaging. Nonsurgical therapy is appropriate if neurological signs or symptoms, instability, deformity, or spinal cord compression are absent. Surgical decompression, debridement, stabilization, and deformity correction are the goals once the decision to perform surgery has been made. The roles of autogenous graft, instrumentation, and allograft have not been clearly delineated with Class I data, but we believe that spinal stability and decompression override creation of an environment that can be completely sterilized by antibiotic drugs.

\section{References}

1. Albert TJ, Vacarro A: Postlaminectomy kyphosis. Spine 23: 2738-2745, 1998 
2. Babinchak TJ, Riley DK, Rotheram EB Jr: Pyogenic vertebral osteomyelitis of the posterior elements. Clin Infect Dis 25: 221-224, 1997

3. Bartels JW, Brammer RE: Cervical osteomyelitis with prevertebral abscess formation. Otolaryngol Head Neck Surg 102: 180-182, 1990

4. Battista RA, Baredes S, Krieger A, et al: Prevertebral space infections associated with cervical osteomyelitis. Otolaryngol Head Neck Surg 108:160-166, 1993

5. Bonfiglio M, Lange TA, Kim YM: Pyogenic vertebral osteomyelitis. Disk space infections. Clin Orthop 96:234-247, 1973

6. Carragee EJ: The clinical use of magnetic resonance imaging in pyogenic vertebral osteomyelitis. Spine 22:780-785, 1997

7. Carragee EJ: Pyogenic vertebral osteomyelitis. J Bone Joint Surg Am 79:874-880, 1997

8. Carragee EJ, Kim D, van der Vlugt T, et al: The clinical use of erythrocyte sedimentation rate in pyogenic vertebral osteomyelitis. Spine 22:2089-2093, 1997

9. Carragee EJ, Kim DH: A prospective analysis of magnetic resonance imaging findings in patients with sciatica and lumbar disc herniation. Correlation of outcomes with disc fragment and canal morphology. Spine 22:1650-1660, 1997

10. Chelsom J, Solberg CO: Vertebral osteomyelitis at a Norwegian university hospital 1987-97: clinical features, laboratory findings and outcome. Scand J Infect Dis 30:147-151, 1998

11. Colmenero JD, Jimenez-Mejias ME, Sanchez-Lora FJ, et al: Pyogenic, tuberculous, and brucellar vertebral osteomyelitis: a descriptive and comparative study of 219 cases. Ann Rheum Dis 56:709-715, 1997

12. Craig FS: Vertebral-body biopsy. J Bone Joint Surg Am 38: 93-102, 1956

13. Currier BL: Spinal infections, in An HS (ed): Principles and Techniques of Spine Surgery. Baltimore: Williams \& Wilkins, 1998, pp 567-603

14. Cyna AM, Bell KR, Flood LM: Cervical osteomyelitis following tonsillectomy. Anaesthesia 52:1084-1087, 1997

15. Dimar JR, Carreon LY, Glassman SD, et al: Treatment of pyogenic vertebral osteomyelitis with anterior debridement and fusion followed by delayed posterior spinal fusion. Spine 29: 326-332, 2004

16. Eismont FJ, Bohlman HH, Soni PL, et al: Pyogenic and fungal vertebral osteomyelitis with paralysis. J Bone Joint Surg Am 65:19-29, 1983

17. Ell SR, Parker AJ, Limb D, et al: Osteomyelitis of the cervical spine following laryngectomy. J Laryngol Otol 106: 1096-1097, 1992

18. Emery SE, Chan DP, Woodward HR: Treatment of hematogenous pyogenic vertebral osteomyelitis with anterior debridement and primary bone grafting. Spine 14:284-291, 1989

19. Faidas A, Ferguson JV Jr, Nelson JE, et al: Cervical vertebral osteomyelitis presenting as a retropharyngeal abscess. Clin Infect Dis 18:992-994, 1994

20. Fraser RD, Osti OL, Vernon-Roberts B: Iatrogenic discitis: the role of intravenous antibiotics in prevention and treatment. An experimental study. Spine 14:1025-1032, 1989

21. Frederickson B, Yuan H, Olans R: Management and outcome of pyogenic vertebral osteomyelitis. Clin Orthop 131:160-167, 1978

22. Frot-Martin B, Carlier RY, Morand-Blot V, et al: Zenker's diverticulum associated with multilevel cervical osteomyelitis. Spine 26:E193-E197, 2001

23. Garcia A Jr, Grantham SA: Hematogenous pyogenic vertebral osteomyelitis. Am J Orthop 42:429-436, 1960

24. Graziano GP, Sidhu KS: Salvage reconstruction in acute and late sequelae from pyogenic thoracolumbar infection. J Spinal Disord 6:199-207, 1993

25. Hadjipavlou AG, Mader JT, Necessary JT, et al: Hematogenous pyogenic spinal infections and their surgical management. Spine 25:1668-1679, 2000
26. Heary RF, Hunt CD, Krieger AJ, et al: HIV status does not affect microbiologic spectrum or neurologic outcome in spinal infections. Surg Neurol 42:417-423, 1994

27. Hlavin ML, Kaminski HJ, Ross JS, et al: Spinal epidural abscess: a ten-year perspective. Neurosurgery 27:177-184, 1990

28. Jeanneret B, Magerl F: Treatment of osteomyelitis of the spine using percutaneous suction/irrigation and percutaneous external spinal fixation. J Spinal Disord 7:185-205, 1994

29. Jensen AG, Espersen F, Skinhoj P, et al: Increasing frequency of vertebral osteomyelitis following Staphylococcus aureus bacteraemia in Denmark 1980-1990. J Infect 34:113-118, 1997

30. Kaiser JA, Holland BA: Imaging of the cervical spine. Spine 23:2701-2712, 1998

31. Khanna RK, Malik GM, Rock JP, et al: Spinal epidural abscess: evaluation of factors influencing outcome. Neurosurgery 39: 958-964, 1996

32. Korovessis P, Sidiropoulos P, Piperos G, et al: Spinal epidural abscess complicated closed vertebral fracture. A case report and review of literature. Spine 18:671-674, 1993

33. Kurimoto M, Endo S, Ohi M, et al: Pyogenic osteomyelitis of an invaginated odontoid process with rapid deterioration of high cervical myelopathy: a case report. Acta Neurochir 140: 1093-1094, 1998

34. Lam CH, Ethier R, Pokrupa R: Conservative therapy of atlantoaxial osteomyelitis. A case report. Spine 21:1820-1823, 1996

35. Liebergall M, Chaimsky G, Lowe J, et al: Pyogenic vertebral osteomyelitis with paralysis. Prognosis and treatment. Clin Orthop 269:142-150, 1991

36. Lifeso RM: Pyogenic spinal sepsis in adults. Spine 15: 1265-1271, 1990

37. Lowe J, Kaplan L, Liebergall M, et al: Serratia osteomyelitis causing neurological deterioration after spine fracture. A report of two cases. J Bone Joint Surg Br 71:256-258, 1989

38. Malawski SK, Lukawski S: Pyogenic infection of the spine. Clin Orthop 272:58-66, 1991

39. Matsui H, Hirano N, Sakaguchi Y: Vertebral osteomyelitis: an analysis of 38 surgically treated cases. Eur Spine J 7:50-54, 1998

40. McGuire RA, Eismont FJ: The fate of autogenous bone graft in surgically treated pyogenic vertebral osteomyelitis. J Spinal Disord 7:206-215, 1994

41. McHenry MC, Easley KA, Locker GA: Vertebral osteomyelitis: long-term outcome for 253 patients from 7 Clevelandarea hospitals. Clin Infect Dis 34:1342-1350, 2002

42. Mendelson GM, Hunt JB, Baron JH: Cervical osteomyelitis and magnetic resonance imaging. J R Soc Med 86:298-299, 1993

43. Modic MT, Feiglin DH, Piraino DW, et al: Vertebral osteomyelitis: assessment using MR. Radiology 157:157-166, 1985

44. Musher DM, Thorsteinsson SB, Minuth JN, et al: Vertebral osteomyelitis. Still a diagnostic pitfall. Arch Intern Med 136: 105-110, 1976

45. Newlands SD, Makielski KH: Cervical osteomyelitis after percutaneous transtracheal ventilation and tracheotomy. Head Neck 18:295-298, 1996

46. Nolla-Sole JM, Mateo-Soria L, Rozadilla-Sacanell A, et al: Role of technetium-99m diphosphonate and gallium-67 citrate bone scanning in the early diagnosis of infectious spondylodiscitis. A comparative study. Ann Rheum Dis 51:665-667, 1992

47. Ottolenghi CE, Schajowicz F, Deschant FA: Aspiration biopsy of the cervical spine. Technique and results in thirty-four cases. J Bone Joint Surg Am 46:715-733, 1964

48. Pratt JN, Munro EA, Kirby BM: Osteomyelitis of the atlantooccipital region as a sequela to a pharyngeal stick injury. $\mathbf{J}$ Small Anim Pract 40:446-448, 1999

49. Rath SA, Neff U, Schneider O, et al: Neurosurgical management of thoracic and lumbar vertebral osteomyelitis and discitis in adults: a review of 43 consecutive surgically treated patients. Neurosurgery 38:926-933, 1996 


\section{Diagnosis and management of adult pyogenic spinal osteomyelitis}

50. Robinson RA, Smith GW: Anterolateral cervical disc removal and interbody fusion for cervical disc syndrome. Bull Johns Hopkins Hosp 96:223-224, 1955

51. Saban KL, Ghaly RF: Spinal cervical infection: a case report and current update. J Neurosci Nurs 30:105-109, 114-115, 1998

52. Sakamoto M, Ichimura K, Tayama N, et al: Cervical vertebral osteomyelitis revisited: a case of retropharyngeal abscess and progressive muscle weakness. Otolaryngol Head Neck Surg 121:657-660, 1999

53. Sanchez J, Jimenez-Escrig A, Saldana C, et al: Cervical epidural abscess: approaches to diagnosis. J Neurosurg Sci 36: $121-125,1992$

54. Sapico FL: Microbiology and antimicrobial therapy of spinal infections. Orthop Clin North Am 27:9-13, 1996

55. Sapico FL, Montgomerie JZ: Pyogenic vertebral osteomyelitis: report of nine cases and review of the literature. Rev Infect Dis 1:754-776, 1979

56. Sapico FL, Montgomerie JZ: Vertebral osteomyelitis. Infect Dis Clin North Am 4:539-550, 1990

57. Schimmer RC, Jeanneret C, Nunley PD, et al: Osteomyelitis of the cervical spine: a potentially dramatic disease. J Spinal Disord Tech 15:110-117, 2002

58. Shad A, Shariff S, Fairbank J, et al: Internal fixation for osteomyelitis of cervical spine: the issue of persistence of culture positive infection around the implants. Acta Neurochir 145: 957-960, 2003

59. Siroky MB, Moylan R, Austen G Jr, et al: Metastatic infection secondary to genitourinary tract sepsis. Am J Med 61: 351-360, 1976

60. Spies EH, Stucker R, Reichelt A: Conservative management of pyogenic osteomyelitis of the occipitocervical junction. Spine 24:818-822, 1999

61. Stoker DJ, Kissin CM: Percutaneous vertebral biopsy: a review of 135 cases. Clin Radiol 36:569-577, 1985

62. Suchomel P, Buchvald P, Barsa P, et al: Pyogenic osteomyelitis of the odontoid process: single stage decompression and fusion. Spine 28:E239-E244, 2003

63. Tampieri D, Weill A, Melanson D, et al: Percutaneous aspira- tion biopsy in cervical spine lytic lesions. Indications and technique. Neuroradiology 33:43-47, 1991

64. Tandon N, Vollmer DG: Infections of the spine and spinal cord, in Winn HR (ed): Youmans Neurological Surgery, ed 5. Philadelphia: Saunders, 2004, Vol 4, pp 4363-4394

65. Wiedau-Pazos M, Curio G, Grusser C: Epidural abscess of the cervical spine with osteomyelitis of the odontoid process. Spine 24:133-136, 1999

66. Wiesseman GJ, Wood VE, Kroll LL, et al: Pseudomonas vertebral osteomyelitis in heroin addicts. Report of five cases. J Bone Joint Surg Am 55:1416-1424, 1973

67. Wiltse LL: The history of spinal disorders, in Frymoyer JW (ed): The Adult Spine: Principles and Practice. New York: Raven Press, 1991, Vol 1, pp 3-41

68. Wood GW II: Infections of spine, in Canale ST (ed): Campbell's Operative Orthopaedics, ed 9. St. Louis: Mosby, 1998, Vol 3, pp 3093-3124

69. Wurtz R, Quader Z, Simon D, et al: Cervical tuberculous vertebral osteomyelitis: case report and discussion of the literature. Clin Infect Dis 16:806-808, 1993

70. Yang EC, Neuwirth MG: Pseudomonas aeruginosa as a causative agent of cervical osteomyelitis. Case report and review of the literature. Clin Orthop 231:229-233, 1988

71. Yazawa S, Ohi T, Sugimoto S, et al: Cervical spinal epidural abscess following acupuncture: successful treatment with antibiotics. Intern Med 37:161-165, 1998

72. Young WF, Weaver M: Isolated pyogenic osteomyelitis of the odontoid process. Scand J Infect Dis 31:512-515, 1999

73. Zeidman SM, Thompson K, Ducker TB: Complications of cervical discography: analysis of 4400 diagnostic disc injections. Neurosurgery 37:414-417, 1995

Manuscript received October 29, 2004

Accepted in final form November 4, 2004.

Address reprint requests to: Frank L. Acosta Jr., M.D., Department of Neurological Surgery, University of California, San Francisco, 505 Parnassus Avenue, Moffitt Hospital M779, Box 0112, San Francisco, California 94143. email: acostaf@ neurosurg.ucsf.edu. 